Check for updates

Cite this: Chem. Commun., 2018, 54, 1363

Received 12th November 2017, Accepted 13th January 2018

DOI: $10.1039 / c 7 c c 08706 c$

rsc.li/chemcomm

\section{Fluorescent squaramides as anion receptors and transmembrane anion transporters $\dagger$}

\author{
Xiaoping Bao, (D) ${ }^{\text {ab }}$ Xin Wu, (D) ${ }^{c}$ Stuart N. Berry, (D) acd Ethan N. W. Howe, (D) \\ Young-Tae Chang (D) ef and Philip A. Gale (D) $* c$
}

A series of squaramide-based anion transporters functionalised with the 1,8-naphthalimide fluorophore has been developed for improved ionophoric activity and fluorescent imaging in cells.

The transport of chloride ions across cell membranes is an important physiological process, which regulates intra- and extracellular $\mathrm{pH}$, membrane potential, and cellular volume that are crucial to many biological processes including cell migration, proliferation and differentiation. ${ }^{1}$ Intracellular chloride concentrations are regulated by naturally occurring anion channels in biological systems. A number of diseases, including cystic fibrosis (CF), involve malfunctioning ion channels (these diseases are collectively known as channelopathies). ${ }^{2}$ Development of small molecule synthetic anion transporters (anionophores) $^{3}$ capable of restoring chloride permeability across lipid bilayers has been proposed as a new approach to treating this class of disease. ${ }^{4}$ In addition, anionophores have been reported to alter $\mathrm{pH}$ and ionic gradients between intracellular compartments, which may lead to cytotoxicity, affording the possibility of using these systems as anticancer agents. ${ }^{5}$

Our group have previously reported fluorescent anion transporters based on naphthalimide-(thio)urea conjugates and

\footnotetext{
${ }^{a}$ Chemistry, University of Southampton, Southampton, SO17 1BJ, UK

${ }^{b}$ State Key Laboratory Breeding Base of Green Pesticide and Agricultural Bioengineering, Key Laboratory of Green Pesticide and Agricultural Bioengineering, Ministry of Education, Center for Research and Development of Fine Chemicals, Guizhou University, Guiyang 550025, China

${ }^{c}$ School of Chemistry, The University of Sydney, NSW 2006, Australia.

E-mail: philip.gale@sydney.edu.au

${ }^{d}$ Singapore Bioimaging Consortium, Agency for Science, Technology and Research ( ${ }^{*}$ STAR), Singapore 138667, Singapore

${ }^{e}$ Center for Self-assembly and Complexity, Institute for Basic Science (IBS), Pohang 37673, Republic of Korea

${ }^{f}$ Department of Chemistry, Pohang University of Science and Technology (POSTECH), Pohang 37673, Republic of Korea

$\dagger$ Electronic supplementary information (ESI) available: Compounds synthesis, NMR binding studies, fluorescent titrations, membrane transport studies, and fluorescent imaging in cells. CCDC 1530149. For ESI and crystallographic data in CIF or other electronic format see DOI: $10.1039 / \mathrm{c} 7 \mathrm{cc} 08706 \mathrm{c}$
}

demonstrated their potential in studying the partitioning, localisation and action of these fluorescent anionophores within living cells using fluorescence imaging techniques. ${ }^{6}$ Those compounds, however, show modest anion transport efficacy compared with our most active transporters. ${ }^{7}$ To improve the anion transport rate potentially allowing the use of fluorescent transporters at lower doses, we decided to use squaramide instead of (thio)urea as the anion binding site and functionalise it with a 1,8-naphthalimide fluorophore. ${ }^{8}$ Compared with the most extensively-utilised urea and thiourea groups for anion complexation, the squaramide group confers the advantage of enhanced anion-binding affinities ${ }^{9}$ which has been shown to benefit anion transport efficacy in artificial liposomes and cells. ${ }^{10}$ Herein we report the synthesis of four novel fluorescent squaramide-based anion transporters 1-4 (Fig. 1) and study of their anion binding and transmembrane transport properties as well as their live-cell imaging capabilities.

Compounds 1-4 were readily obtained by reaction of 4-(4-aminobutylamino)-1,8-naphthalimide with squarate monoesters (see ESI $\dagger$ for synthetic details and characterisation data). Single crystals of compound 4 suitable for X-ray diffraction analysis were obtained by slow evaporation of a DMSO solution of 4 at room temperature. The crystal structure (Fig. 2) showed

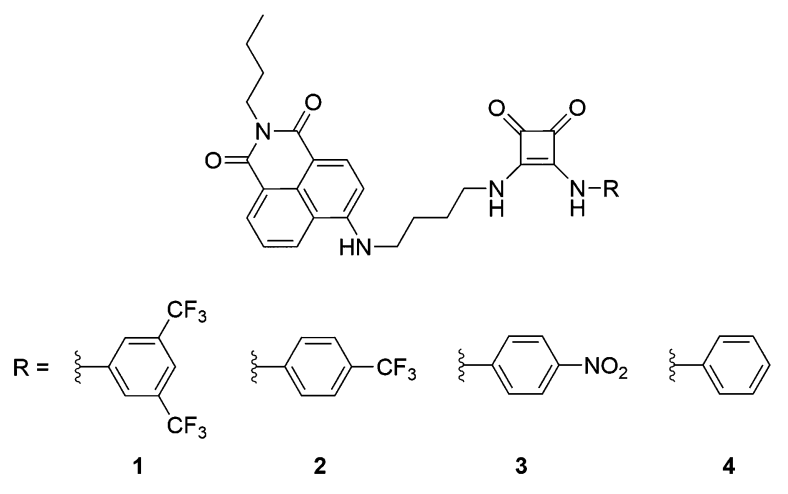

Fig. 1 Structures of compounds $\mathbf{1 - 4}$. 


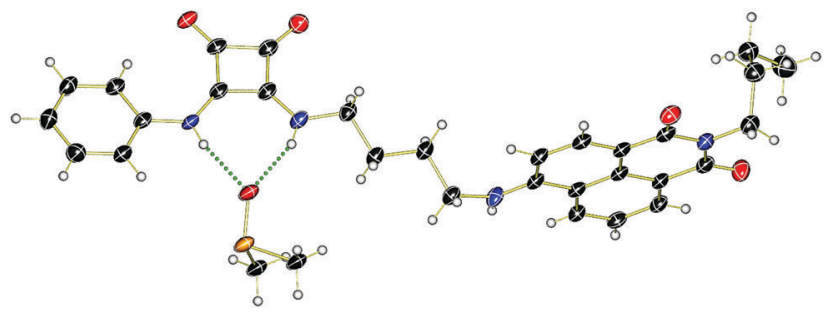

Fig. 2 Crystal structure of 4.DMSO complex (CCDC 1530149).†

that compound $\mathbf{4}$ formed a 1:1 complex with DMSO via two squaramide $\mathrm{NH} \cdots \mathrm{O}$ hydrogen bonds $(\mathrm{N} \cdots \mathrm{O}$ distances of 2.834(2) and 2.821(3) $\AA$ and $\mathrm{N}-\mathrm{H} \cdots \mathrm{O}$ bond angles of $163.3^{\circ}$ and $155.1^{\circ}$, respectively). The 4 -amino $\mathrm{NH}$ group of the naphthalimide moiety was not involved in the hydrogen bonding interaction with the DMSO solvate, despite the presence of a flexible 1,4-butylene linker between the naphthalimide and squaramide moieties.

The binding affinities of compounds 1-4 for chloride (as the tetra- $n$-butylammonium salt) were evaluated via ${ }^{1} \mathrm{H}$ NMR titrations in DMSO- $d_{6}$ (ESI $\dagger$ ). For compound 1 upon the addition of $\mathrm{Cl}^{-}$, significant downfield shifts were observed for the two

Table 1 Binding constants $\left(\mathrm{M}^{-1}\right)$ for the binding of compounds 1-4 to $\mathrm{Cl}^{-}, \mathrm{NO}_{3}{ }^{-}$and $\mathrm{H}_{2} \mathrm{PO}_{4}{ }^{-}$(tetrabutylammonium salts used for titrations) in DMSO $-d_{6}$ at $298 \mathrm{~K}$ as well as the corresponding Hammett constants $\left(\sigma_{\mathrm{p}}\right)$ of the substituents

\begin{tabular}{lllll}
\hline Compound & $K_{\mathrm{a}}{ }^{a}\left(\mathrm{Cl}^{-}\right)$ & $K_{\mathrm{a}}{ }^{b}\left(\mathrm{NO}_{3}{ }^{-}\right)$ & $K_{\mathrm{a}}\left(\mathrm{H}_{2} \mathrm{PO}_{4}{ }^{-}\right)$ & $\sigma_{\mathrm{p}}$ \\
\hline $\mathbf{1}$ & 520 & $<10$ & $>10^{4 c}$ & $0.85^{e}$ \\
$\mathbf{2}$ & 240 & $<10$ & $>10^{4 c}$ & $0.54^{f}$ \\
$\mathbf{3}$ & 290 & $<10$ & $>10^{4 c}$ & $0.78^{f}$ \\
$\mathbf{4}$ & 160 & $<10$ & $4400^{d}$ & $0.00^{f}$
\end{tabular}

${ }^{a}$ The values of binding constant $\left(K_{\mathrm{a}}\right)$ were calculated by fitting the chemical shift changes of two squaramide NH resonances upon addition of TBACl assuming a $1: 1$ global fitting binding model. ${ }^{b}$ All the proton signals were found to undergo negligible change in their chemical shifts during the titration process. ${ }^{c}$ The binding constants were estimated based on the chemical shift changes of aromatic $\mathrm{CH}$ protons (adjacent to squaramide $\mathrm{NH}$ ), due to the disappearance of $\mathrm{NH}$ signals during the titration process. ${ }^{d}$ This value was determined by simultaneously fitting the chemical shift changes of two squaramide $\mathrm{NHs}$ and the naphthalimide 4-NH resonances upon addition of TBACl, using a 1:1 global fitting binding model. ${ }^{e}$ The $\sigma$ value for $3,5-\mathrm{bisCF}_{3}-\mathrm{Ph}$ substitution was obtained from the $\mathrm{p} K_{\mathrm{a}}$ of 3,5-bis(trifluoromethyl)benzoic acid (J. Org: Chem., 2016, 81, 12116-12127). ${ }^{f}$ Values obtained from ref. Chem. Rev., 1991, 91, 165-195. squaramide $\mathrm{NHs}(\Delta \delta>+1.3 \mathrm{ppm})$ as well as two aromatic $\mathrm{CH}$ protons from the $3,5-\mathrm{bisCF}_{3}-\mathrm{Ph}$ group $(\Delta \delta=+0.22 \mathrm{ppm})$. In contrast, the naphthalimide $4-\mathrm{NH}$ only underwent a very slight downfield shift $(\Delta \delta=+0.05 \mathrm{ppm})$ over the course of the titration process, suggesting weak or no interaction of this proton with chloride. A global fitting analysis assuming a 1:1 binding model was employed to provide the binding constant $\left(K_{\mathrm{a}}\right)$, by simultaneous fitting of the chemical shift changes of two squaramide NHs as a function of added chloride. ${ }^{11}$ As shown in Table 1, all compounds bound $\mathrm{Cl}^{-}$with affinities ranging from $160-520 \mathrm{M}^{-1}$. The relative strength of anion binding $(\mathbf{1}>3>2>4)$ correlated with the Hammett constants $\left(\sigma_{\mathrm{p}}\right)$ of their substituents. Much weaker binding was observed for $\mathrm{NO}_{3}{ }^{-}\left(K_{\mathrm{a}}<10 \mathrm{M}^{-1}\right)$ and stronger binding for the more basic anion $\mathrm{H}_{2} \mathrm{PO}_{4}{ }^{-}\left(4400 \mathrm{M}^{-1}\right.$ determined for $\mathbf{4}$, and higher affinity of $>10^{4} \mathrm{M}^{-1}$ was found for more acidic compounds 1-3). Different from $\mathrm{Cl}^{-}$binding, the complexation of tetrahedral $\mathrm{H}_{2} \mathrm{PO}_{4}{ }^{-}$by compound 4 seems to involve the naphthalimide $4-\mathrm{NH}(\Delta \delta=+1.24 \mathrm{ppm})$ in addition to two squaramide NHs.

The chloride-nitrate transport activities of compounds 1-4 across lipid bilayers were evaluated using liposome-based techniques based on a chloride ion-selective electrode (ISE, Fig. 3). ${ }^{12}$ Briefly, 1-palmitoyl-2-oleoyl-sn-glycero-3-phosphocholine (POPC) unilamellar vesicles (mean diameter $200 \mathrm{~nm}$ ) were loaded with $\mathrm{NaCl}$ (489 mM, buffered to $\mathrm{pH} 7.2$ with $5 \mathrm{mM}$ sodium phosphate), and then suspended in a $\mathrm{NaNO}_{3}$ solution (489 mM, buffered to $\mathrm{pH} 7.2$ with $5 \mathrm{mM}$ sodium phosphate). The $\mathrm{Cl}^{-} / \mathrm{NO}_{3}{ }^{-}$ transport process was initiated by the addition of DMSO solution of compounds 1-4 to these vesicles, and the resultant chloride efflux was monitored using an ISE. Hill analysis ${ }^{13}$ was conducted by following chloride efflux at different concentrations of transporters (in mol\% with respect to lipid concentration) to obtain $\mathrm{EC}_{50}$ value (the concentration of transporter needed to achieve $50 \%$ chloride efflux in $270 \mathrm{~s}$ ) and Hill coefficient $n$ (indicating the stoichiometry of the formed complex during the transmembrane transport process ${ }^{14}$ ). As shown in Table 2, compound 1 with two $\mathrm{CF}_{3}$ substituents possessed the best transport activity with a substantially lower $\mathrm{EC}_{50}$ value $(0.15 \mathrm{~mol} \%)$ than previously reported naphthalimide-(thio)ureas $(>0.4 \mathrm{~mol} \%){ }^{6}$ The anion transport activity of the compounds $(\mathbf{1}>\mathbf{3}>\mathbf{2}>\mathbf{4})$ followed the same trend as their anion binding affinities. The Hill coefficient values of $\sim 1$ is consistent with a mobile carrier mechanism via formation of a 1:1 receptor-anion complex (Fig. 4).
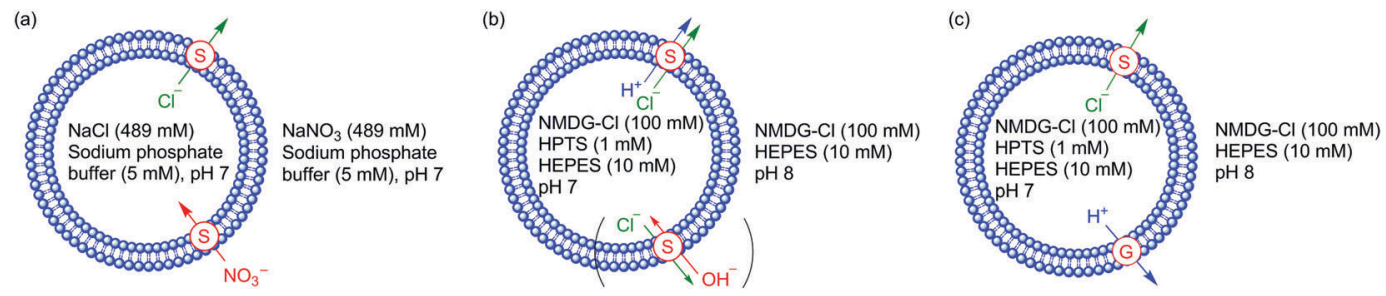

(S) = Squaramide G = Gramicidin D (Proton Channel)

Fig. 3 Schematic illustration of the assays utilised for measuring the $\mathrm{Cl}^{-} / \mathrm{NO}_{3}{ }^{-}$antiport using the ISE (a); the $\mathrm{H}^{+} / \mathrm{Cl}^{-}$symport or OH $\mathrm{OH}^{-} / \mathrm{Cl}^{-}$antiport using the NMDG-Cl assay in the absence (b) and presence (c) of Gramicidin D (proton channel). 
Table 2 Summary of anion transport parameters $\left(k_{\text {ini }}, \mathrm{EC}_{50}\right.$ and $\left.n\right)$ and calculated lipophilicity values $(c \log P)$ for compounds 1-4

\begin{tabular}{lllllll}
\hline Comp. & $k_{\text {ini }}{ }^{a}$ & $\begin{array}{l}\mathrm{EC}_{50,270 s^{b}}{ }^{b} \\
\left(\mathrm{Cl}^{-} / \mathrm{NO}_{3}{ }^{-}\right)\end{array}$ & $n^{c}$ & $\begin{array}{l}\mathrm{EC}_{50,200 s}{ }^{d} \\
\left(\mathrm{Cl}^{-}-\mathrm{H}^{+} / \mathrm{OH}^{-}\right)\end{array}$ & $n^{c}$ & $c \log P^{e}$ \\
\hline $\mathbf{1}$ & 1.2 & 0.15 & 0.9 & 0.018 & 1.5 & 5.8 \\
$\mathbf{2}$ & 0.57 & 0.63 & 0.8 & 0.055 & 1.3 & 5.4 \\
$\mathbf{3}$ & 1.0 & 0.26 & 1.0 & 0.041 & 1.4 & 4.9 \\
$\mathbf{4}$ & 0.33 & 2.07 & 0.9 & 0.27 & 1.8 & 5.1
\end{tabular}

${ }^{a}$ Values determined by fitting the plot of relative chloride release $(y)$ versus time $(x)$ for $2 \mathrm{~mol} \%$ transporter to lipid to an asymptotic function $y=a-b \times c^{x}$. The initial rate of chloride release $\left(k_{\text {ini }}\right.$ in $\left.\% \mathrm{~s}^{-1}\right)$ was obtained by $-b \ln (c) .{ }^{b}$ Molar percentage with respect to lipid needed to obtain $50 \%$ chloride efflux at $270 \mathrm{~s}$ from the $\mathrm{Cl}^{-} / \mathrm{NO}_{3}{ }^{-}$exchange assay. ${ }^{c}$ Hill coefficient from Hill analysis. ${ }^{d}$ Molar percentage with respect to lipid needed to obtain $50 \%$ chloride efflux at $200 \mathrm{~s}$ from the HPTS assay. $e^{e}$ The $\log P$ values were calculated via VCCLab.

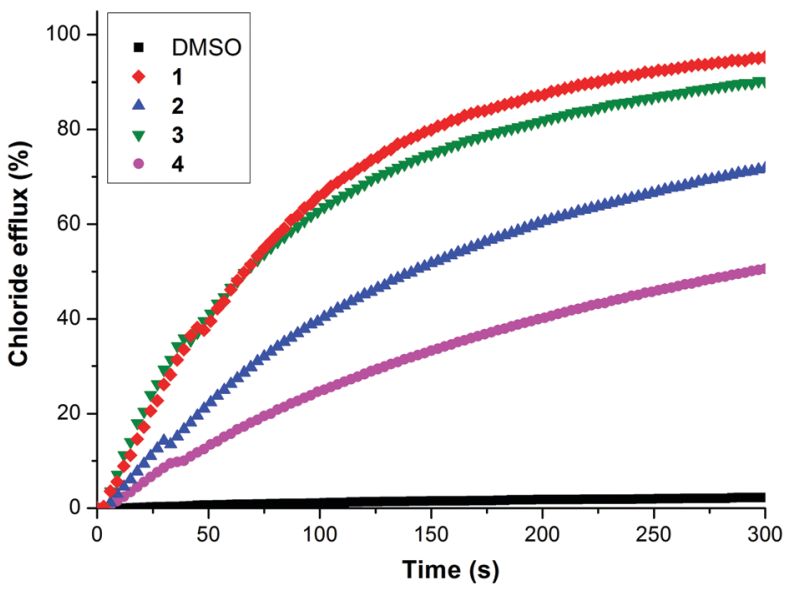

Fig. 4 Chloride efflux promoted by compounds $1-4$ (2 mol\% compound to lipid) from unilamellar POPC vesicles containing $489 \mathrm{mM} \mathrm{NaCl}$ buffered to $\mathrm{pH} 7.2$ with $5 \mathrm{mM}$ phosphate salts, suspended in $489 \mathrm{mM} \mathrm{NaNO}$ buffered to $\mathrm{pH} 7.2$ with $5 \mathrm{mM}$ phosphate salts. At the endpoint of each experiment (300 s), the detergent (Triton X-100) was added to lyse the vesicles and calibrate the electrode to $100 \%$ chloride efflux. Each point represents the average of three trials. Pure DMSO was utilised as a control.

Previous studies have shown that anion transporters could dissipate the $\mathrm{pH}$ gradient across lipid bilayer in vesiclebased experiments, via $\mathrm{H}^{+} / \mathrm{Cl}^{-}$symport or $\mathrm{OH}^{-} / \mathrm{Cl}^{-}$antiport mechanism. ${ }^{15}$ In order to explore this possibility, a series of assays were performed using fluorescent dye HPTS (8-hydroxypyrene1,3,6-trisulfonic acid) as $\mathrm{pH}$ indicator and $N$-methyl-D-glucamine (NMDG) chloride as a chloride ion source. ${ }^{16}$ Briefly, POPC liposomes were firstly prepared containing $1 \mathrm{mM}$ HPTS and $100 \mathrm{mM}$ NMDG-Cl buffered to $\mathrm{pH}$ 7.0, and suspended in an external solution of $100 \mathrm{mM}$ NMDG-Cl buffered to pH 7.0. Then, NMDG ( $5 \mathrm{mM}$ ) was added as a base pulse to create a transmembrane $\mathrm{pH}$ gradient $(\Delta \mathrm{pH}=1.0)$ and then the transporter was immediately added into the above suspension to trigger ion transport process and the resultant dissipation of $\mathrm{pH}$ gradient (Fig. 3b). As shown in Fig. 5, the $\mathrm{H}^{+} / \mathrm{Cl}^{-}$cotransport (or $\mathrm{OH}^{-} / \mathrm{Cl}^{-}$antiport) took place. To quantitatively evaluate the $\mathrm{Cl}^{-}-\mathrm{H}^{+} / \mathrm{OH}^{-}$transport activity of compounds 1-4, Hill analysis was also carried out to give the corresponding values of $\mathrm{EC}_{50}$ and Hill coefficient $(n)$.

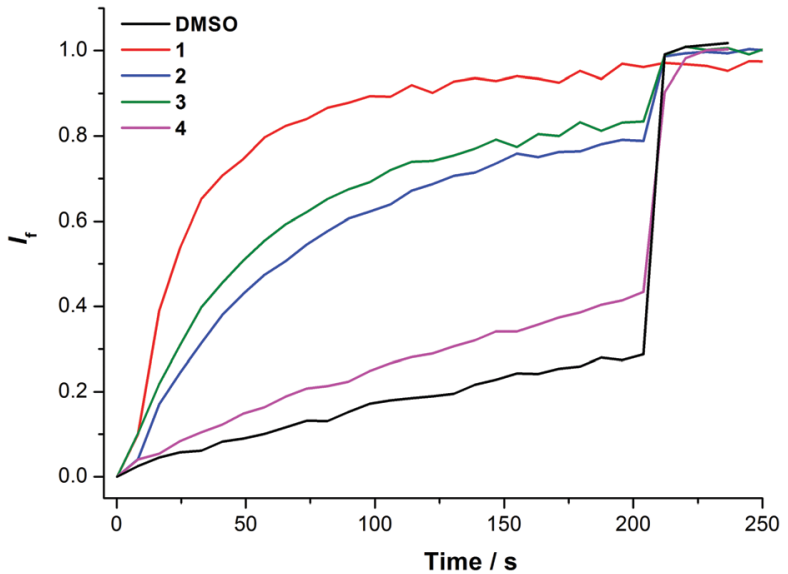

Fig. $5 \mathrm{H}^{+} / \mathrm{Cl}^{-}$symport or $\mathrm{OH}^{-} / \mathrm{Cl}^{-}$antiport facilitated by compounds 1-4 (0.2 mol\% compound to lipid) from unilamellar POPC vesicles containing both $1 \mathrm{mM} \mathrm{HPTS}$ and $100 \mathrm{mM}$ NMDG-Cl buffered to $\mathrm{pH} 7.0$ with $10 \mathrm{mM}$ HEPES buffer and suspended in an external solution of $100 \mathrm{mM}$ NMDG-Cl buffered to pH 7.0 with 10 mM HEPES buffer. At the endpoint of each experiment $(200 \mathrm{~s})$, the detergent was added to lyse the vesicles and collapse the $\mathrm{pH}$ gradient for calibration of HPTS fluorescence. Pure DMSO was utilised as a control experiment.

From Table 2, the $\mathrm{H}^{+} / \mathrm{Cl}^{-}$cotransport (or $\mathrm{OH}^{-} / \mathrm{Cl}^{-}$antiport) activity of 1-4 followed the same order as that of the $\mathrm{Cl}^{-} / \mathrm{NO}_{3}{ }^{-}$ exchange. The presence of proton channel gramicidin D did not affect the rate of $\mathrm{pH}$ gradient dissipation of all compounds (ESI $\dagger$ ), suggesting that $\mathrm{H}^{+}$or $\mathrm{OH}^{-}$transport is not rate-limiting in this assay (acceleration of $\mathrm{H}^{+}$transport by gramicidin $\mathrm{D}$ did not improve the overall transport rate). ${ }^{16}$ Note that for all compounds the $\mathrm{EC}_{50}$ values in the ISE $\mathrm{Cl}^{-} / \mathrm{NO}_{3}{ }^{-}$exchange assay is about 10 times the values in the HPTS assay, which is consistent with the fact that the ISE assay requires a higher ion flux $\left(\sim 500 \mathrm{mM}\right.$ of $\mathrm{Cl}^{-}$and $\left.\mathrm{NO}_{3}{ }^{-}\right)$than the HPTS assay

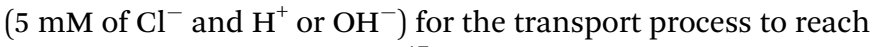
thermodynamic equilibrium. ${ }^{17}$

The presence of the 1,8-naphthalimide fluorophore within compounds 1-4 allows them to be used for live cell imaging. This was explored using the human lung carcinoma A549 cell line. Fluorescence micrographs were collected after incubation of the cells with compounds 1-4 $(1.0 \mu \mathrm{M})$ for 24 hours and then free compound was washed away with PBS buffer. Interestingly, the most active transporter 1 exhibited bright green fluorescence within the cytoplasm of A549 cells (Fig. 6), confirming its ability to fluorescently stain the cells. Importantly, compound $\mathbf{1}$ up to $100 \mu \mathrm{M}$ exhibited no toxicity to A549 cells as determined using a CCK-8 assay (ESI $\dagger$ ). In comparison, compound 2 showed a poor fluorescent staining of A549 cells even at $10 \mu \mathrm{M}$. The second most active transporter $\mathbf{3}$ demonstrated a marginal fluorescence in A549 cells, which became stronger with increasing concentration; however, a deliverability issue at $10 \mu \mathrm{M}$ impeded its ability to stain cells at high concentrations, under which conditions precipitation was observed. The least active transporter $\mathbf{4}$ did not show any detectable cell staining at all concentrations (ESI $\dagger$ ).

In summary, a series of squaramide-based fluorescent anion receptors were synthesized, bearing a 1,8-naphthalimide moiety 


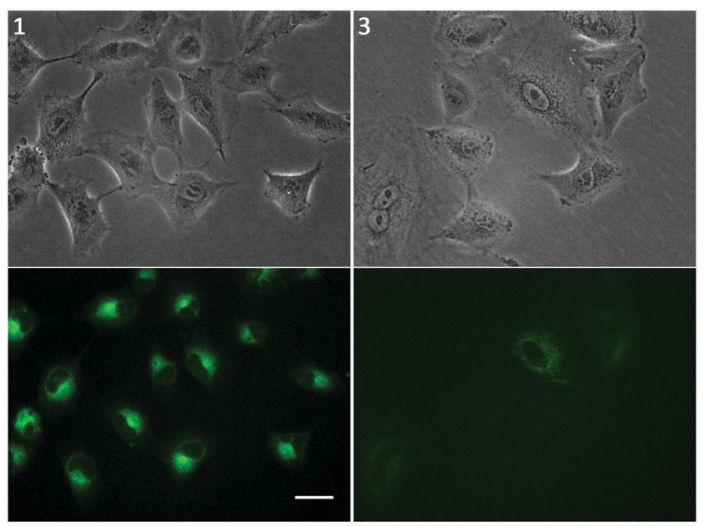

Fig. 6 Fluorescent micrographs of A549 cells after incubation with compounds 1 (1.0 $\mu \mathrm{M}$, left) and $3(1.0 \mu \mathrm{M}$, right) for 24 hours. The brightfield and fluorescent images were displayed in the upper and lower row, respectively. Scale bar: $25 \mu \mathrm{m}$.

as the fluorophore. Their anion binding and transmembrane transport properties towards biologically important chloride ions were investigated. The results indicated that these compounds have moderate to relatively strong affinities towards $\mathrm{Cl}^{-}$in DMSO- $d_{6}$, with the highest affinity of $520 \mathrm{M}^{-1}$ observed for the most acidic compound 1. Compounds 1-4 facilitate chloride transport into the vesicles via $\mathrm{Cl}^{-} / \mathrm{NO}_{3}{ }^{-}$antiport and $\mathrm{Cl}^{-} / \mathrm{H}^{+}$symport (or functionally equivalent $\mathrm{Cl}^{-} / \mathrm{OH}^{-}$antiport) mechanisms. The relative transmembrane transport activities of these compounds were mainly dictated by their chloride affinities. The most active transporter 1 was found to have the highest efficiency in fluorescent staining of living A549 cells among the squaramides while being nontoxic and possessing substantially higher anion transport activity than previously reported fluorescent anion transporters. ${ }^{6}$ These results represent an important step forward in developing highly active fluorescent transmembrane anion transporters that are useful for studying the sub-cellular localisation and pharmacokinetics of anion transporters in biological systems.

We thank Shanghai R\&S Biotechnology Co., Ltd (Shanghai, China) for performing the cytotoxicity test of compound $\mathbf{1}$. XB thanks the China Scholarship Council (201506675004) for financial support. XW and ENWH thank the University of Sydney for postdoctoral fellowships. SNB thanks A*STAR for an ARAP studentship. PAG thanks the University of Sydney and the Australian Research Council (DP170100118 and DP180100612) for funding.

\section{Conflicts of interest}

There are no conflicts to declare.

\section{Notes and references}

1 (a) F. M. Ashcroft, Ion Channels and Disease: Channelopathies, Academic Press, San Diego, 2000; (b) B. Hille, Ionic Channels of Excitable Membranes, Sinauer Associates, Sunderland, MA, 2001; (c) P. A. Gale, R. Pérez-Tomás and R. Quesada, Acc. Chem. Res., 2013, 46, 2801-2813.

2 (a) C. Higgins, Nature, 1992, 358, 536; (b) J. Y. Choi, D. Muallem, K. Kiselyov, M. G. Lee, P. J. Thomas and S. Muallem, Nature, 2001, 410, 94-97.

3 (a) P. A. Gale, J. T. Davis and R. Quesada, Chem. Soc. Rev., 2017, 46, 2497-2519; (b) P. A. Gale, E. N. W. Howe and X. Wu, Chem, 2016, 1, 351-422.

4 H. Li, J. J. Salomon, D. N. Sheppard, M. A. Mall and L. J. V. Galietta, Curr. Opin. Pharmacol., 2017, 34, 91-97.

5 (a) V. Soto-Cerrato, P. Manuel-Manresa, E. Hernando, S. CalabuigFariñas, A. Martínez-Romero, V. Fernández-Dueñas, K. Sahlholm, T. Knöpfel, M. García-Valverde, A. M. Rodilla, E. Jantus-Lewintre, R. Farràs, F. Ciruela, R. Pérez-Tomás and R. Quesada, J. Am. Chem. Soc., 2015, 137, 15892-15898; $(b)$ N. Busschaert, M. Wenzel, M. E. Light, P. Iglesias-Hernández, R. Pérez-Tomás and P. A. Gale, J. Am. Chem. Soc., 2011, 133, 14136-14148; (c) J. L. Sessler, L. R. Eller, W.-S. Cho, S. Nicolaou, A. Aguilar, J. T. Lee, V. M. Lynch and D. J. Magda, Angew. Chem., Int. Ed., 2005, 44, 5989-5992.

6 S. N. Berry, V. Soto-Cerrato, E. N. W. Howe, H. J. Clarke, I. Mistry, A. Tavassoli, Y.-T. Chang, R. Pérez-Tomás and P. A. Gale, Chem. Sci., 2016, 7, 5069-5077.

7 (a) L. E. Karagiannidis, C. J. E. Haynes, K. J. Holder, I. L. Kirby, S. J. Moore, N. J. Wells and P. A. Gale, Chem. Commun., 2014, 50, 12050-12053; (b) C. M. Dias, H. Li, H. Valkenier, L. E. Karagiannidis, P. A. Gale, D. N. Sheppard and A. P. Davis, Org. Biomol. Chem., 2018, DOI: $10.1039 / \mathrm{c} 7 \mathrm{ob} 02787 \mathrm{~g}$.

8 (a) D. Wu, A. C. Sedgwick, T. Gunnlaugsson, E. U. Akkaya, J. Yoon and T. D. James, Chem. Soc. Rev., 2017, 46, 7105-7123; (b) S. Banerjee, E. B. Veale, C. M. Phelan, S. A. Murphy, G. M. Tocci, L. J. Gillespie, D. O. Frimannsson, J. M. Kelly and T. Gunnlaugsson, Chem. Soc. Rev., 2013, 42, 1601-1618; (c) X.-P. Bao, L. Wang, L. Wu and Z.-Y. Li, Supramol. Chem., 2008, 20, 467-472; (d) T. Gunnlaugsson, P. E. Kruger, P. Jensen, J. Tierney, H. D. P. Ali and G. M. Hussey, J. Org. Chem., 2005, 70, 10875-10878.

9 (a) S. J. Edwards, H. Valkenier, N. Busschaert, P. A. Gale and A. P. Davis, Angew. Chem., Int. Ed., 2015, 127, 4675-4679; (b) V. Amendola, L. Fabbrizzi, L. Mosca and F.-P. Schmidtchen, Chem. - Eur. J., 2011, 17, 5972-5981; (c) V. Amendola, G. Bergamaschi, M. Boiocchi, L. Fabbrizzi and M. Milani, Chem. - Eur. J., 2010, 16, 4368-4380.

10 (a) N. Busschaert, I. L. Kirby, S. Young, S. J. Coles, P. N. Horton, M. E. Light and P. A. Gale, Angew. Chem., Int. Ed., 2012, 51, 4426-4430; (b) N. Busschaert, S.-H. Park, K.-H. Baek, Y. P. Choi, J. Park, E. N. W. Howe, J. R. Hiscock, L. E. Karagiannidis, I. Marques, V. Félix, W. Namkung, J. L. Sessler, P. A. Gale and I. Shin, Nat. Chem., 2017, 9, 667-675.

11 (a) P. Thordarson, Chem. Soc. Rev., 2011, 40, 1305-1323; (b) www. supramolecular.org.

12 (a) E. N. W. Howe, N. Busschaert, X. Wu, S. N. Berry, J. Ho, M. E. Light, D. D. Czech, H. A. Klein, J. A. Kitchen and P. A. Gale, J. Am. Chem. Soc., 2016, 138, 8301-8308; (b) J. T. Davis, O. Okunola and R. Quesada, Chem. Soc. Rev., 2010, 39, 3843-3862.

13 A. V. Hill, Biochem. J., 1913, 7, 471-480.

14 S. Bhosale and S. Matile, Chirality, 2006, 18, 849-856.

15 A. Vargas Jentzsch, D. Emery, J. Mareda, S. K. Nayak, P. Metrangolo, G. Resnati, N. Sakai and S. Matile, Nat. Commun., 2012, 3, 905.

16 For a discussion of this assay, see X. Wu, L. W. Judd, E. N. W. Howe, A. M. Withecombe, V. Soto-Cerrato, H. Li, N. Busschaert, H. Valkenier, R. Pérez-Tomás, D. N. Sheppard, Y.-B. Jiang, A. P. Davis and P. A. Gale, Chem, 2016, 1, 127-146.

17 Y. Yang, X. Wu, N. Busschaert, H. Furuta and P. A. Gale, Chem. Commun., 2017, 53, 9230-9233. 